\title{
AE Waveform analysis of Delamination in GFRP Composite materials during drilling
}

\author{
A. Sudha J., B. Sampathkumar S. and C. Vijaya A
}

\begin{abstract}
Fiber reinforced plastics have been widely used for manufacturing aircraft and spacecraft structural parts because of their particular mechanical and physical properties such as high strength to weight ratio and also stiffness. Drilling of these composite materials can be considered as a critical operation owing to their tendency to delaminate when subjected to mechanical stresses. With regard to the quality of machined component, the principal drawbacks are related to surface delamination, fiber / resin pull out and inadequate surface roughness of the hole wall. Among the defects caused by drilling, delamination appears to be the most critical. Delamination is responsible for the rejection of approximately $60 \%$ of the components produced in the aircraft industry (Khasabha, 2004). Therefore, it is very important to detect the delamination undergone by the composite material. This necessitates an online technique, which can be used to monitor and measure the delamination as it occurs. Acoustic emission (AE), an online monitoring tool, is ideally suited for this purpose. The work discusses the experimental investigations carried out on Glass Fiber reinforced plastic (GFRP) composite specimens in which the acquired $\mathrm{AE}$ data is analysed. $\mathrm{AE}$ waveform obtained during drilling of GFRP composites are analysed and presented. The results clearly indicate that $\mathrm{AE}$ parameters as well as $\mathrm{AE}$ waveforms can be used to identify the optimum cutting condition on drilling glass fiber reinforced composite laminate and also can be used for monitoring the drilling process.
\end{abstract}

Index Terms-AE, GFRP, Delamination, Drilling, Waveform

\section{INTRODUCTION}

Glass fibre reinforced plastic (GFRP) composites are most widely used in aerospace, automobile and marine industries owing to their omni potential properties such as a high strength to weight ratio, and a high specific stiffness. The machining of GFRP is necessitated to manufacture near net-shaped components. The machining of a composite is different from the conventional machining of metals due to the composites anisotropic and non homogeneous nature. Drilling is the most important machining operation. While drilling, the two phases, namely the fibre and matrix, which are in coexistence, behave differently than when they are separate. The most common problems which occur while drilling GFRP composites are delamination, matrix crazing and fibre pull-out etc. The fibre orientation relative to the path of the cutting edge varies continuously from ply to ply

\section{Manuscript received December 1, 2008}

A. Research Scholar, Department of Production Technology, MIT, Anna University, Chromepet, Chennai-44

B. Professor, Department of Production Technology, MIT, Anna University, Chromepet, Chennai-44

C. Lecturer, SRM University, Chennai., Tamilnadu, India which also poses problems. The delamination of fibres from matrix due to excessive force is a major problem in machining, which results in the lowering of bearing strength and is detrimental to the durability by reducing the in-service life under fatigue loads. [1, 2, 3]

Therefore, in order to suit the structural design requirements these delaminations have to be detected quantified and correlated to the process variables so that they are optimized to achieve the desired hole quality. Usage of unconventional techniques such as water jet, laser beams etc. has been explored. However, each of these methods appears to have their own limitations when put into practical use. For example, water jet cutting washes away the relatively softer matrix and large fibre protrusions are left behind on the drilled surface. Laser cutting produces intense heat in the ablative region, which burns off the matrix and degrades the area around the hole.[4] The quality of a finished hole in composite materials amongst other indices is governed by fibre protrusions, splintering and delaminations, the most crucial among these being delamination damage.

Therefore, the most appropriate method for the evaluation of the quality of the drilled holes in composites calls for an on-line method. Some on-line methods including optical, thermal, vibration monitoring, chip and wear-debri analysis, which have been reported for metal cutting, can also be used for composite machining. However, each has its own deficiencies when put into actual practice. So the $\mathrm{AE}$ technique as an inherent in-process monitoring tool that has several advantages to the methods mentioned above, could become the most appropriate tool when fully developed, for qualitative and quantitative evaluation of the drilled hole quality.

Hence the goal of this research was to apply AE in the drilling of composite laminates and to understand the different events that occur from the time the drill comes in contact with the surface to the time when the process is complete

\section{LITERATURE SURVEY}

Several authors published papers on drilling of composite material and they focussed on the problems and damages caused during drilling of composite. Delamination is one of the damages in drilling a laminated composite. The literature survey regarding delamination by some of the authors is discussed below.

A.M.Abrao \& et al (2007) presented a literature survey on the machining of composite materials, more specifically on the drilling of glass and carbon fibre reinforced plastics. Aspects such as tool materials and geometry, machining 
parameters and their influence on the thrust force and torque were investigated. They also paid special attention to the delamination damage and assessed the quality of holes.[5]

P.T.Cole (1985) concentrated on the advanced techniques which can be used to analyse AE from composites by making use of modern computer technology to carry out rapid data processing, location and analysis which are not possible previously.[6]

J.Ramkumar \& et al., studied the effect of workpiece vibration on drilling of GFRP laminates using different types of drills. It was observed that by vibrating the workpiece during drilling the parameters such as thrust, tool wear, temperature, power and Acoustic emission (RMS value) are very much reduced.

H.Hocheng et al. made a comprehensive analysis on delamination in drilling of composite materials in the various drill bits. The critical thrust force at the onset of delamination was predicted and compared with the twist drill.[7]

J.P. Davim et al. studied delamination in drilling carbon fiber reinforced plastics using design experiments and inferred that cutting velocity has the highest physical influence on the delamination factor in CFRP laminate for the drills.[8]

\section{PRINCIPLE OF ACOUSTIC EMISSION PROCESS}

Acoustic Emission (AE) is the class of phenomena whereby an elastic wave, in the range of ultrasound usually between $20 \mathrm{KHz}$ and $1 \mathrm{MHz}$, is generated by the rapid release of energy from the source within a material. The elastic wave propagates through the solid to the surface, where it can be recorded by one or more sensors. The sensor is a transducer that converts the mechanical wave into an electrical signal. In this way information about the existence and location of possible sources is obtained.

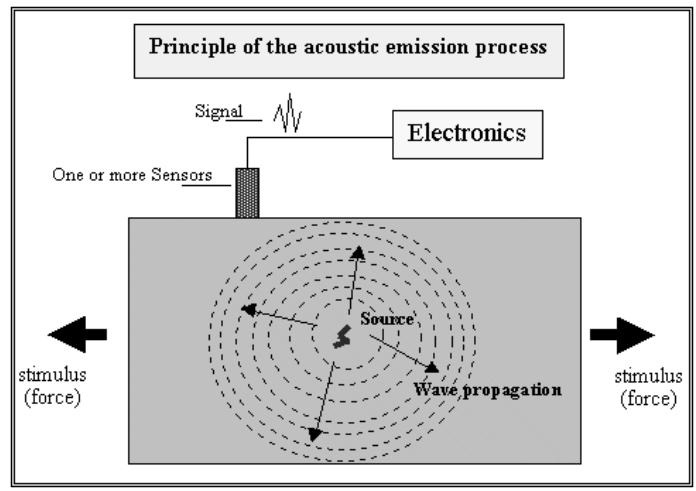

Fig 1 Principle of the AE process

\section{A. AE Process Chain}

A process chain always exists at AE testing. Mechanical stress has to be produced within the test object, which is usually done by applying external forces. The behavior of the material and the starting point of the release of elastic energy, e.g. by crack formation, are influenced by the material properties and the environment conditions. The elastic wave propagating through the material is detected and converted into the electrical AE signal by the $\mathrm{AE}$ sensors. The $\mathrm{AE}$ System processes the AE signal, converts the received wave packets into feature data sets, determines the source locations, calculates statistics, and displays them graphically and numerically. So-called parametric channels measure the environmental conditions as well as the external load as reference parameters for the detected $\mathrm{AE}$.

\section{EXPERIMENTAL PROCEDURE \& OBSERVATION}

\section{A. Specimen Preparation}

A Random oriented GFRP composite was prepared by Hand Lay up technique. The specimen was prepared in such a way that the fibres are segregated and accumulated in a region in the matrix. A GFRP composite plate of approximately $5 \mathrm{~mm}$ thickness was prepared. A mixture of Epoxy resin (LY556) and Hardener (HY951) was used for preparation. AE testing was carried out while drilling in the Fibre rich region.

\section{B. Monitoring through AE}

The photograph of experimental setup is shown in Figure 3. A vertical spindle-milling machine was used to drill holes of $4 \mathrm{~mm}$ in the laminates. A miniature type $\mathrm{AE}$ sensor was coupled to the composite specimen using grease and fastened with a cellophane adhesive tape. A preamplifier linked the sensor to the AET signal processor.

The output of the preamplifier was connected to a personal computer with 2 channel peripheral connect interface card of AE systems. AE Post processor was used to plot graphs between different AE parameters, which were acquired in drilling random oriented GFRP.

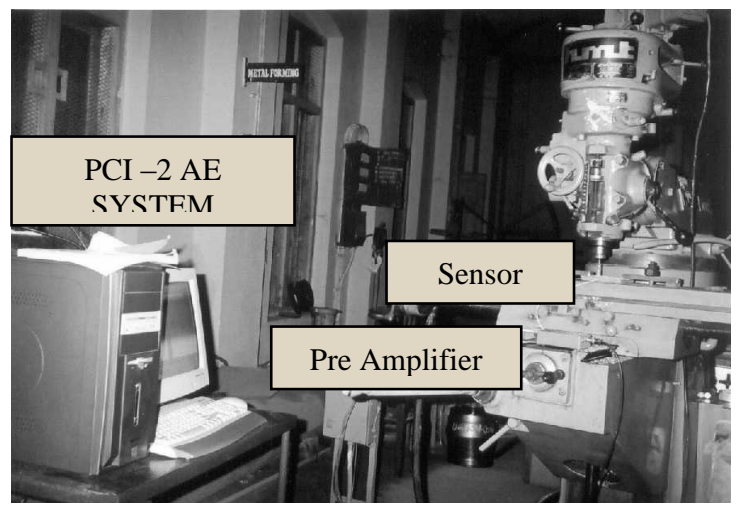

Fig 3 Photograph of experimental setup

A $4 \mathrm{~mm}$ high speed twist drill of point angle $118^{\circ}$ was used to generate holes at cutting velocity in the steps of 7,12 and $28 \mathrm{~m} / \mathrm{min}$ and recordings of the AE response were obtained. No coolant was used during drilling. For each speed 3 holes were drilled. A digital stopwatch was used to note the time interval between drill touch and drill exit. The twist drill was ground after every five holes were drilled to avoid tool wear. Initial experiment was oriented towards understanding the AE response in typical specimen of epoxy (matrix material), fiber cloth and the GFRP laminate as drilling is progressed. This revealed some information to arrive at a useful base line AE data. With this base data, detailed experiments were attempted. The actual experiments were performed above the threshold value of noise.

Experimental observations show that delamination occur both at the exit as well as at the entrance. This suggests two 
distinguishable mechanisms, which are responsible for delamination in each case. They are called push-out at exit and peel-up at entrance.

\section{Monitoring of Drilling of GFRP}

The experiments were carried out on GFRP composite material. The time vs. cumulative AE RMS parameter graphs was used for analysis and the graphs obtained for drilling of random oriented GFRP at different speed are shown in figures 4,5 and 6 . The graph at low cutting velocity of $7 \mathrm{~m} / \mathrm{min}$ (spindle speed $550 \mathrm{rpm}$ ) clearly shows drastic change in slope and has two stages, which correspond to drilling process and push out at exit (figure 4). At cutting velocity of $12 \mathrm{~m} / \mathrm{min}$ (spindle speed of $925 \mathrm{rpm}$ ), the number of stages in cumulative graph is one because of the absence of drastic change in slope and it possesses negligible damage at both entrance and exit as shown in figure 5 .
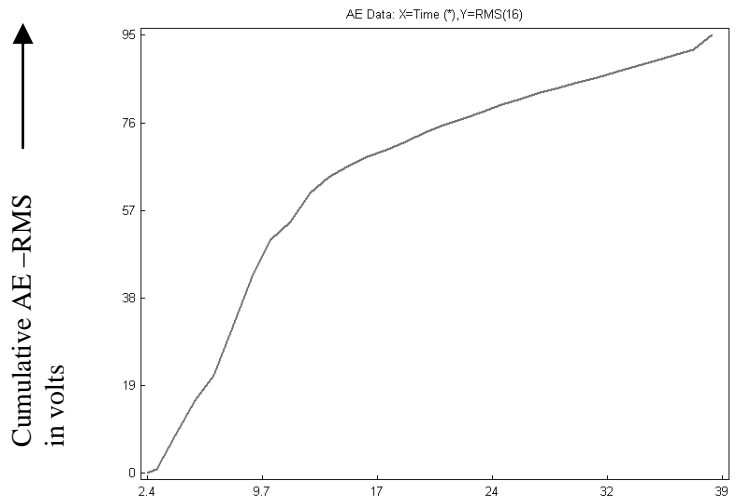

Time in sec

Fig 4 Time vs. Cumulative AE-RMS for cutting velocity of $7 \mathrm{~m} / \mathrm{min}$ : Fiber rich

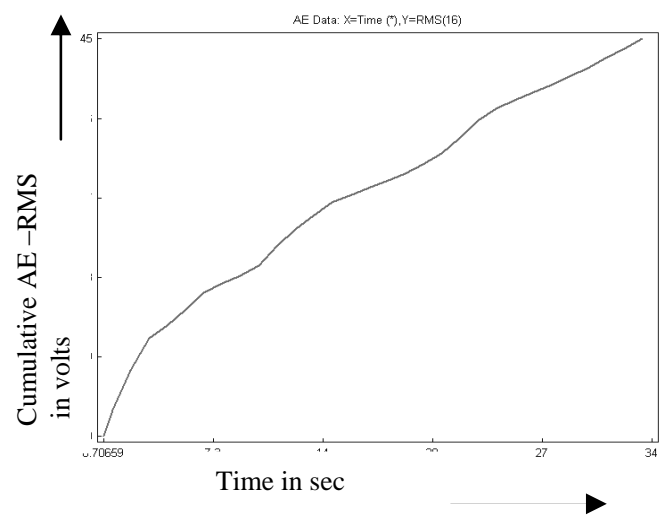

Fig 5 Time vs. Cumulative AE-RMS for cutting velocity of $12 \mathrm{~m} / \mathrm{min}$ : Fiber rich

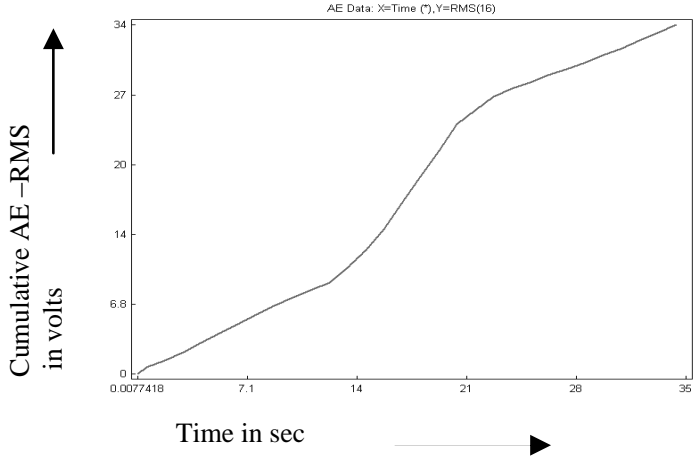

Fig 6 Time vs. Cumulative AE-RMS for cutting velocity of $28 \mathrm{~m} / \mathrm{min}$

At Spindle speed of $2262 \mathrm{rpm}$ (Cutting velocity of 28 $\mathrm{m} / \mathrm{min}$ ), the cumulative graph shows three stages with respect to peel up at entrance, push out at exit and for drilling process as shown in figure 6 .

\section{Selection of Optimum cutting speed}

The optimum spindle speed is the one, which produces less damage on GFRP laminates both at entrance as well as at exit. The delamination damage can be quantified by a factor called delamination factor (J.Paulo Davim and Pedro Reis, 2003) [8] and it can be defined as the ratio of maximum diameter at damage zone to original diameter of drill (Figure 7). The value of delamination factor $\left(\mathrm{F}_{\mathrm{d}}\right)$ can be determined from the following equation.

$$
\mathrm{F}_{\mathrm{d}}=\mathrm{D}_{\max } / \mathrm{D}
$$

Where $\mathrm{D}_{\max }$ is maximum diameter of damage hole in $\mathrm{mm}$ and $\mathrm{D}$ is diameter of the hole in $\mathrm{mm}$.

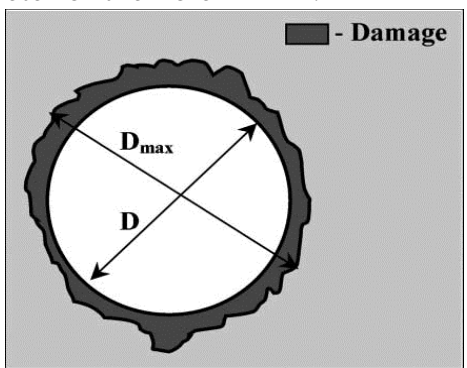

Fig 7 Delamination damage around the periphery of drilled hole

For cutting velocity of $12 \mathrm{~m} / \mathrm{min}$ (spindle speed of 925 rpm), the Delamination Factor was found to be unity, which is reflected in figure 5 and table 1 where there is no drastic change in slope and indicates no delamination. Thus it is inferred that AE can also be used to identify the optimum cutting speed.

TABLE 1 SELECTION OF OPTIMUM SPEED AFTER ASSESSMENT OF DELAMINATION DAMAGE

\begin{tabular}{cccc}
\hline $\begin{array}{l}\text { Cutting } \\
\text { velocity } \\
\text { in } \\
\mathrm{m} / \mathrm{min}\end{array}$ & $\begin{array}{l}\text { Number of } \\
\text { stages in } \\
\text { cumulative } \\
\text { graphs }\end{array}$ & $\begin{array}{l}\text { Delamination } \\
\text { factor- Peel } \\
\text { up entrance }\end{array}$ & $\begin{array}{l}\text { Delamination } \\
\text { factor -Push } \\
\text { out at exit }\end{array}$ \\
\hline 7 & 2 & 1 & 1.5 \\
\hline 12 & 1 & 1.06 & 1.06 \\
\hline 28 & 3 & 1.5 & 1.5 \\
\hline
\end{tabular}

\section{E. Waveform Analysis of AE RMS Signal}

Basically, there are two types of AE signals, transient and continuous signals. Waveform analysis is used to determine whether AE signal is burst type or continuous type. With transient AE signals, also called bursts, start and end points deviate clearly from background noise. With continuous AE signals, we can see amplitude and frequency variations but the signal never ends.

The waveform for the holes drilled at $7 \mathrm{~m} / \mathrm{min} \& 28 \mathrm{~m} / \mathrm{min}$ at entrance and exit are shown in the figures below. 


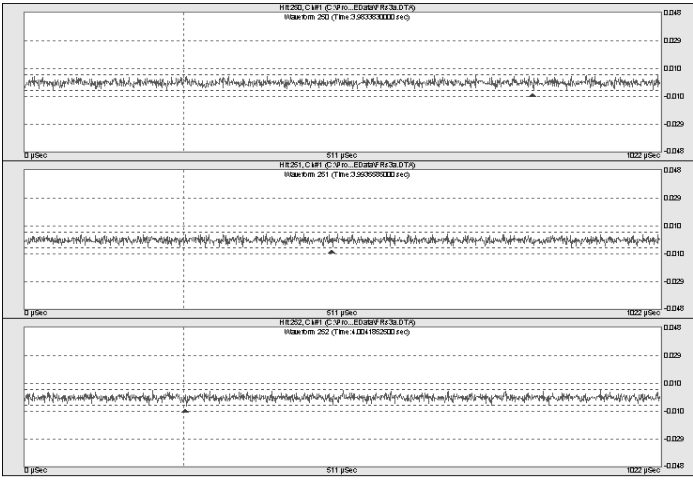

Fig 9 Waveform for drilling at $7 \mathrm{~m} / \mathrm{min}$ (entrance)

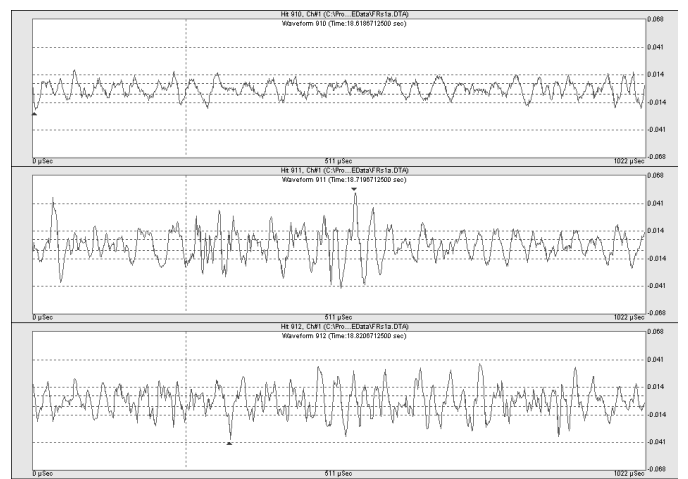

Fig 10 Waveform for drilling at $7 \mathrm{~m} / \mathrm{min}$ (exit)

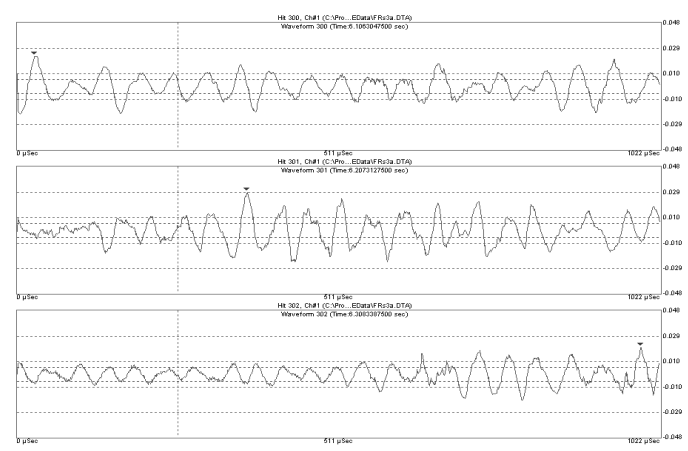

Fig 11 Waveform for drilling at $28 \mathrm{~m} / \mathrm{min}$ (entrance)

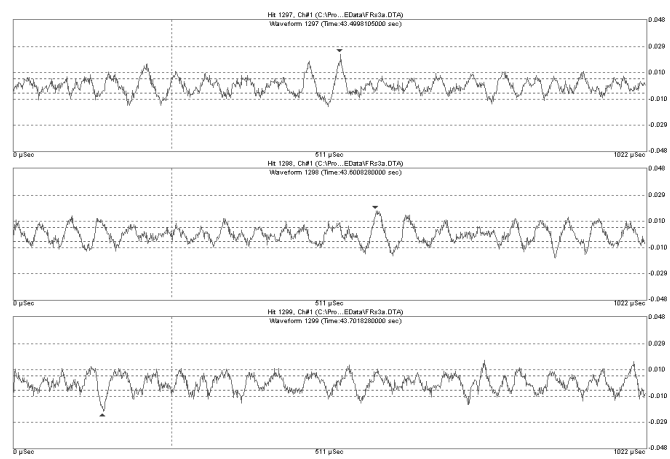

Fig 12 Waveform for drilling at $28 \mathrm{~m} / \mathrm{min}$ (exit)

\section{INFERENCE}

It is found that for the hole drilled at $7 \mathrm{~m} / \mathrm{min}$, the delamination factor is 1 at the entrance which indicates that there is no delamination at the entrance. For the same hole at the entrance, the waveform obtained is a continuous type which also indicates that there is no rapid release of energy because of delamination.

At the exit of the hole drilled at $7 \mathrm{~m} / \mathrm{min}$, the delamination factor is 1.5 which indicates that the delamination occurs at the exit of the hole called Push out at the exit. Similarly the waveform obtained here has burst a type signal which originates from the delamination.

From the waveforms, for the hole drilled at $28 \mathrm{~m} / \mathrm{min}$, it is also observed that the delamination occurs both at the entrance and at the exit which have delamination factor of 1.5 .

\section{CONCLUSIONS}

1. Waveform analysis can be used to monitor the drilling process by the way of classifying the waveform as continuous, mix of continuous and burst and burst which will be for smooth drilling process, onset of delamination and delamination respectively.

2. As long as there is continuous emission of signals, it indicates that there is no delamination. Burst emission is an indication of delamination.

3. Monitoring of drilling of composite using AET indicates damages like delamination at entrance and exit by showing change in slope of cumulative graph of AE RMS signal vs. Time.

\section{REFERENCES}

[1] Koenig WC, Grass P, Willerscheid H (1985) "Machining of fiber reinforced plastics" Annal CIRP 34:537-548.

[2] Cheng H, Puw HY (1992) "On drilling characteristics of fiber reinforced thermo set and thermoplastics" Int J Mach Tools Manufact 32(4):589-592

[3] Komanduri R (1993) "Machining of fiber-reinforced composites" ASME Mech Engin 114:58-644.

[4] S.R.Ravishankar, \& C.R.L.Murthy, "Application of Acoustic Emission in drilling of Composite laminates", NDT \& E International, 33 2000) 429-435.

[5] A.M.Abrao \& et al, "Drilling of Fiber reinforced Plastics: A review" Journal of Materials Processing Technology, 186 (2000) 1-7.

[6] P.T.Cole, "Using Acoustic Emission (AE) to locate and identify defects in Composite structures", Composite Structures, Vol.3. Issues 3-4 (1985) 259-267.

[7] H.Hocheng \& C.K.H.dharan, "Delamination during drilling in Composite laminates in Machining composites", ASME, 3(1988) 3947.

[8] Davim J.P. \& Pedro Reis, " Study of Delamination in drilling Carbon fiber reinforced plastics using Design experiments", Composite Structures, 59 (2003) 481-487. 